\title{
Community and Citizen Participation in Policy Formation and Implementation: a Critical Review of three Case Studies
}

\author{
Wiza Kabaghe ${ }^{1}$, Sylvia Mwanza-Kabaghe $(\mathrm{PhD})^{2}$ \\ ${ }^{1}$ School of Natural Sciences. University of Zambia, Lusaka, Zambia, \\ ${ }^{2}$ School of Education. University of Zambia, Lusaka Zambia
}

\begin{abstract}
This article highlights the phenomenon of participation. The first section of this paper is structured in terms of the Ideals of Participation: what the policy makers try to achieve by introducing civic and community participation in policy formation and implementation and also the Practice of Participation: what are the actual discrepancies between policy intentions and policy outcomes regarding participation. Thesecond section of the paper is based on the theory of two (2) empirical Case Studies in which the ideal and practice are studied and analysed based on the conceptual framework and compared to conclude the findings.
\end{abstract}

\section{INTRODUCTION}

Participation is defined as the act of sharing in the activities of a group or a neighbourhood .It can also be defined as the condition of sharing in common with others as fellows or partners. Participatory development methods are born out of recognition of the uniqueness of an individual as an entity who is capable of making unique contributions to decision-making (Mompati,T and G.Prinsen,2000/ 2011).Participation in terms of efficiency is seen as a tool for achieving better project outcomes and in terms of empowermentparticipation is seen as a process which enhances the capacity of individuals to improve their own lives and facilitates social change to the advantage of disadvantaged or marginalised groups .Others advocate for participation as a way of teaching otherwise powerless citizens to interact with other groups in society (Irvin, R and J.Stansbury, 2004).Citizen participation programs and policies have been launched since the 1950s at all levels of government with the assumption that citizens become actively involved in this process that emerges to be more democratic and more effective.Arguments for enhanced citizen participation often rest on the merits of the process and the belief that an active and committed citizen is better than a passive non- committed citizen.

Arguments highlighting citizen participation focus on the benefits of the process itself as a transformation tool for social change. The advantage of participation is the education of the citizens who will be well informed and involved to understandholistic technical situations and solutions. Most governmentsparticularly the politicians sometimes can use citizen participation as a motivation factor to a more co-operative public when they are involved in the policy making venturesand gain political legitimacy to win votes. Policy makers introduce participation to encourage and empowerthe powerless citizens who will no interact with other groups in society. Popular participation has been seen as a "missing ingredient" to be achieved through fool proof or bureaucratic proof ways of adding "participation components" to projects and activities (Stifel, M and Wolfe, 1994/2011).Most institutions involving community participation helps in breakingthe gridlock for traditional decisionsmaking that would have never been made unilaterally and in turn avoiding litigation costs that have proven to be costly when the public disapproves certain decisions.

\section{Constraints of Civic/Community Participation}

On the other hand, it can be argued that not always is participation a solution for successful development.Depending on the type of situations and project status, citizen participation can also lead to unsuccessfuldevelopment. Some of the arguments that ariseare that sometimesit'scostlyin the contextof time wasted to assemble series of meetings to make decisions in which a single administrator or professional trained to know theconsequences of his or her decisions can react abruptly and produce wonderful outcomes. Even in situations where communities are complacent, 
there is a strong argument for top-down administration simply on grounds of efficiency in which theorists can acknowledges prefer to avoid a protracted series of meetings and accept the mandate of agent decision makers. Citizen participation sometimes lacks the necessary representation due to lack of incentivesas the motivationfactor when attending meetings. They argue that theremain priority is to first provide for their own families .The greatest constraint especially in developing countries is the persistent selfishness by others who see opportunity to influence decision making policy for their own self or favouring their fellow tribe's menand women. Ethnicity can take advantage of participation as the majority ethnic group can dominant decision making against the minority subordinate ethnic groups.

According to literature by Luis Botes and Dingies van Rensburg (2000) they identified constraints of community participation by analysing the dynamics of community participation,particularlyin the south African urban upgrading context .Nine(9) obstacles and impediments (plagues) were exposed which serve to illustrate participatory development as a complex and difficult,through essential and challenging endeavours. Obstacles can be external, internal and a combination of both. The nine plagues included:

1. The paternalistic role of development professionals (experts) that dominate decision making and manipulate instead of facilitating the process. The professionals prefer to know it all without the proper consultation of the citizens on the ground.

2. The inhibiting and prescriptive role of the state in which there main aim of community participation programmes is less about improving conditions for the poor or to modify forms of decision making than maintaining existing power relations in the society and ensuring the silence of the poor.

3. The over-reporting of development success and ignoring its failures making it hard to understand lessons learnt.

4. The Selective participation of people who neither have the capacity nor the desire to participate are involved in the development process.

5. The concentration of hard-issue bias (technological, financial, physical and material) and ignoring the social dimensions of a project the soft-issues bias (community involvement, decision making procedures, organizational development capacity building and empowerment).

6. Conflicting interests groups within end - beneficially communities in which development introduces marginalised communities to limited resources and opportunities, which very much often increases the likelihood of development as a divisive force.

7. The presence of gate-keepers by local elites who oppose decisions when they are against.

8. The excessive pressure for immediate results may force the workers to take matters out of their hands of community people and complete them themselves.

9. And lastly the lack of public interest in becoming involvedas a result of past experiences where expectations were not fulfilled.

\section{Model of PARTiCipation}

There is need for a more complex understanding of issues of efficiency and empowerment in participatory approaches, particularly two key concepts about the nature and role of institutions and the model of individual action.Participationis directly influenced by the new institutionalism. These theories suggest that in order to reduce the cost of individual transactions by allowing the exercise of sanctions for non co-operation, institutions help to formalize mutual expectations of co-operative behaviour. Social institutions are perceived as clever solutions to the problems of trust and malfeasance in economic life as they can make cheating and free riding too costly an activity to engage in (Clever, F, 1999).Social Institutions basically form a platform for citizen participation.

\subsection{Institutionalism}

Mechanisms are put in place for reducing transactions costs and institutionalizing co-operative interactions through the focus on contracts, committees, property rights and basic associations. There is a trend in development literature to acknowledge the importance of social and informal institutions 
than to always concentrate on the analysis and building of formal institutions.Formalization is strongly linked to evolutionism models fromtraditional forms of management to modern forms which are considered desirable and is the focus of much local institutions building on development. A project focus defines institutions functionality as specific to the project task. Committee like institutions have strong trends to emphasize participation through democratic and transparent representation, and a concentration on the voting of representatives.Socially embedded institutions are not better than formal institutions because they can also lead to inequality and exclusion, subordination and vulnerability (Clever, F, 1999).

\subsection{Individual Participation}

The lack of model of individuals and the link to social structure is considered inadequate in the context of participatory approaches. The concept of the rational economic man is so deeply embedded in development thinking that its influence is strongly felt even where development efforts are concerned with activities which are not directly productive with community (Cleaver, F, 1999).Traditionally even though participatory literature is vague on incentives, people are usually persuaded to participate when incentives or allowances are provided. People will find it sensible to participate after they have considered the assurance of individual cost and benefits because it is like a social responsibility and in the interest of community development. Interestingly many policy approaches make significant effort to link participation with social responsibility, to characterize non -participation as irresponsible, and at the same time to define benefitswhich are immediate.It is helpful to see a person positioned in multiple ways with social relations conferred by specific social identities in examining motivation. Development represents a transformation from traditional relations, traditional ways of thinking, traditional ways dealing with health and education, traditional methods of production, to more 'modern' ways (Stiglitz, J. 2002). Non-participation and non compliance maybe both a rational strategy and unconscious practice embedded in routine, social norms and the acceptance of the status quo. (Cleaver, F, 1999).There has been calls to recognize both the costs and benefits of participation for individuals.Individual participation may be negotiated and mediated at household and community shaped by prevailing social norms and structure. Some individuals chose not to participate because they try to avoid to be bound by norms and rules of the associations. It is salutary also to remember that community may be used as a definition of exclusion as well as inclusion, with local entities which may draw on religious, ethnic and locationaldifferences.

\section{Conceptual Framework}

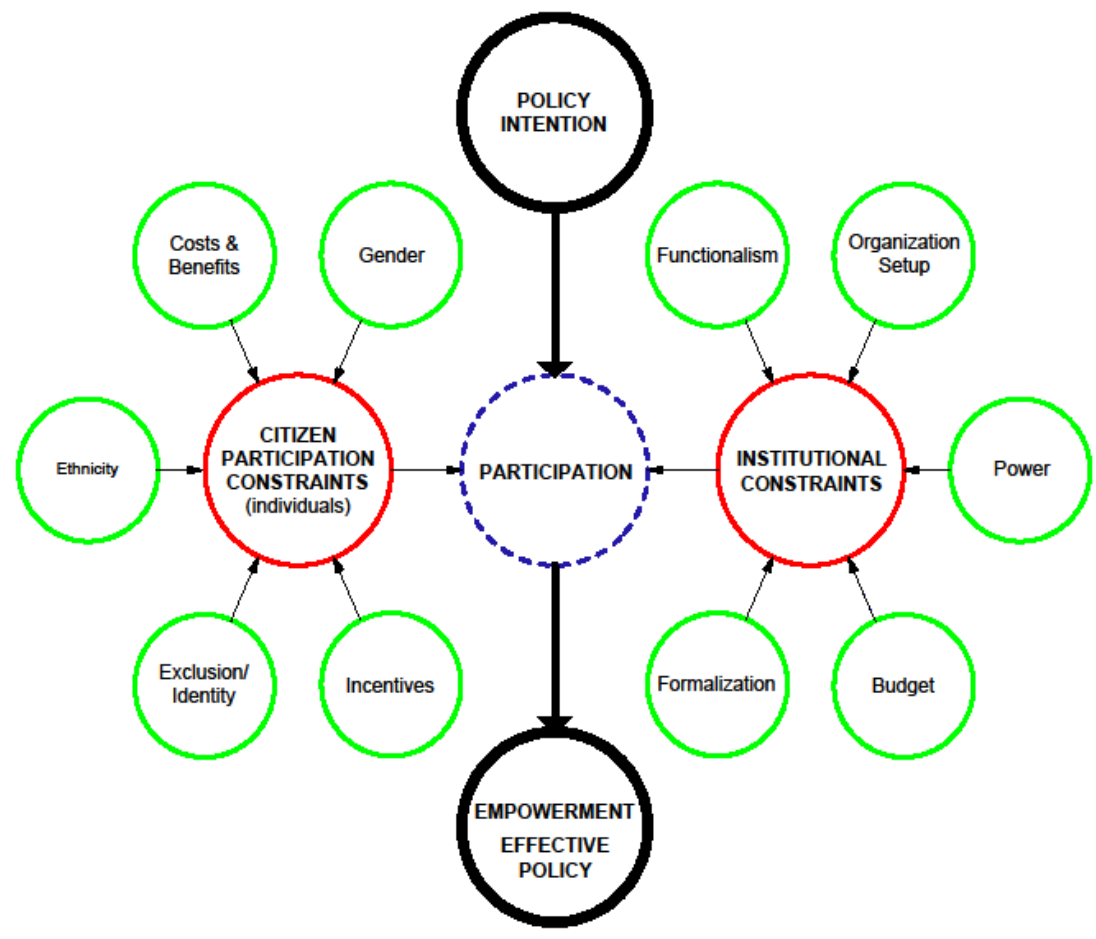


The conceptual framework above shows the constraints in terms of individual and institutional participation that are preventing the policy intention and formulation to be effective and achieved. It shows the actual discrepancies between policy intentions and policy outcomes regarding participation.

\section{RESEARCH QUESTIONS}

1. Why was participation introduced?

2. Has this objective been achieved?

3. What have been the actual constraints of participation?

\section{Case Study 1 - The evolution of COMmunity WATER governance in UChira, TANZANIA: THE IMPLICATIONS FOR EQUALITY OF ACCESS, SUSTAINABILITY AND EFFECTIVENESS.}

\subsection{Introduction}

This case study draws on research of Uchira village water supply in Tanzania to explore the contested nature of community ownership and the complex evolution of a community-owned institution. Assumptions of Uchira Water Association are made concerning the capacity of local communities to manage service delivery and balance sustainable principals and equity. The article concludes with important questions about the role of external agencies and the state in setting and enforcing equity criteria in community-managed initiatives that have created tensions in community - driven development.The case study illustrate that representation itself is not enough to ensure that the needs of the poor andmarginalised are met and that the process of securing and supporting community participation is lengthy and require strong external interventions.

\subsection{Research Data and Methodology}

Uchira is a large village in Moshi Rural District, situated approximately $18 \mathrm{~km}$ from Moshi on the Arusha - Dar-es-Salam highway. According to the wealth ranking, $30 \%$ of villagers are poor, the majority $60 \%$ are middle ranking and the rest $10 \%$ are the wealthiest group. Uchira is a relatively new village with management of piped water scheme resided with village government from 1960 onwards until 1990s, when leakages from the pipes started and population increased causing shortage of piped water for all. Therefore, 1996 is taken as the baseline for this case study. The 2002 Water Policy document places emphasis on decentralization of decision making in particular the participation of water user and local communities in driving projects,managing water and cost bearing and in working with NGO,private sector and other external agents. The policy expects the local communities to pay a portion of capitals costs, in cash and in kind or through user fees for the rehabilitation, operations, maintenance and extensions of existing schemes. The policy tend to ignore issues of equity and sustainability at micro level.

This case study of Uchira Water User Association (UWUA) was aimed at exploring the tensions of the policy targets. Data of field work was collectedin the period from December 2003 until August 2005.The approach adopted was exploratory and combined extensive and intensive research methods.Semi structured interviews, life history interviewing ,observation of participants, photographs, and secondary documents(such as minutes of meetings) were used to profile the community in terms of constructing a wealth ranking and livelihood profile.These data base were then used for stratified samples of interviews with 128 water users and further used to purposively select 42 life-history interviewees in order to construct a profile of participation of people of different age ,gender,wealth,in collection activities in general. The institutional evolution of the water user association was tracked through observations and interviews undertaken at a sample of public taps, with water taps attendants and key personnel within the association and at the village council.

\subsection{Institutional model of UWUA}

From its origin the Uchira Water User Association (UWUA) has developed into a professional organisation. It managed water supplies in Uchira,with sizeable annual turnover of about 19 million Tanzanian shillings(TZS) in 2004, seen by donors as an ideal example of community managed water supply .The UWUA constitution sought to establish institutional arrangement for sustainable management through charging customers for water and seeking funds to bring about community and social welfare development in general.UWUA is characterised by GTZ as a community owned 
institution with professional staff running the operations, maintaining water supply and even collecting revenue.UWUA is self-sufficient in terms of being able to cover the salaries of staff and carry out day to day maintenance and operations. Capacity building activities were implemented and funded by GTZ.Community Ownership of the UWUA is formalized through membership of the Association .The criteria for membership recognises the contribution of community members through labour or cash donation. The gender balanceof 50\% representation appeared to be observed and formalized. The number of individual members of UWUA reported has rose from 133 in 2002 to 200 in 2004, but unfortunately represented a small minority of water users in the village.Non-member were allowed to purchase water but could not participate in the management of the Association. Only full registered members were entitled to vote and attend board meetings. And to be a full member a person was required to make financial and work contribution to the establishment of the scheme, they should be 18years and above and they should pay a yearly membership fee of $\$ 1$ first year and $\$ 2$ per year on afterwards.

Only a minority of water users have actually chosen to join the UWUA as members because of the high membership fees but, nevertheless a significant proportion of the wealthier population also refused to become members of the scheme. Some interviewees saw the scheme as a closed group thattreated the associationlike a private company.The majority of the water users were not aware of how the scheme is run.Records of consultative meetings showed a low level of attendance for public meetings held in 2004, which were mostly facilitated by external consultants rather than by local staff that may have perceived that the scheme is not owned by community.Some interviewees also felt that too much money is wasted on workshops and refreshments for staff members. Many interviewees felt that they were just included simply as means of providing cheap labour not in terms of making decision.The evolution of the UWUA is characterised by both internal and external power struggles .The village council was automatically a member of the UWUA board although without voting rights .In 2004, it was agreed by the UWUA management board that the rehabilitation and extension of water supply required 2 days per week of communal labour and this decision caused resentment and tension as people felt they were already contributing through payment of water. The village council had to confiscate goods from people who did not participate and also fined or threatened with force by the use of village militia.In May 2004, a new manager was appointed and who revised the UWUA constitution to clarify and separate the community and professional responsibilities within the organisation which was accompanied by a handpicked group of wealthy and powerful residents.

\subsection{Conclusion}

This case study was mostly centred on the institutional constraints of participation identifying key variables of the conceptual framework like Power of the Association with the help of GTZ which helped the organisation of the institution. Asustainable budget for the institutethrough the collection ofwater bills from water users at contested rates. Formalization of the water association as a recognised institute which proved to be functional and organisation setup of institutionby employing and incorporating outside professionalsin water supply projects operations. In many ways the Uchira Water User Association (UWUA) as an institution was a success in terms of increasing water supply to villagers and a better place to live with $50 \%$ representation of women (gender) in decision making. This research shows that we cannot assume that managing water at local level leads to neither broad community ownership nor ownership in the interest of all. In practice, local community ownership was heavily contested, and the organisation showed a shift towards professionalism and achieved the intended policy targets hence empowering the residents with water.

\section{CASE STUdY 2 - UNEXPECTED NEGATIVE OUTCOMES OF COMMUNITY PARTICIPATION ON LOW-COST HOUSING PROJECTS IN SOUTH AFRICA}

\subsection{Introduction}

It is often believed and argued that individual (user) participation is crucial for performance of lowcost housing projectsbecause they know what is best for the most appropriate decisions about their housing solutions .This case study looked at Non-governmental Organisations (NGOs) working in housing projects in cape town (South Africa) having based their interventions in community participation initiatives that respond to what they call "decisions of the community". However, this community-based approach has had unexpected consequences that perpetuate some of the 
shortcomings in South African cities. The unexpected negative consequences found in three (3) case studies show that, the overall performance of low-cost housing projects does not depend on community participation and that some of the mechanisms and the advantages of community participation needed to be reconsidered.

\subsection{Research Methods and Fieldwork}

This research was conducted between December 2005 and December 2006. The three case studies are located in the periphery of cape town namely Netreg, Freedom park and Mfuleni settlements . The authors used analytical generalization by comparing first the patterns of the three case study and later the patterns found in this research with patterns found in previous research in order to obtain valuable generalization. Five officers of the NGO were interviewed through semi-structured interviews. The architect and two persons responsible for community empowerment were questioned about the project on three different meetings including other participants on the project .Official reports and documents were collected and analysed.The researchers attended five sessions of the construction committees (three in Mfuleni and two in Netreg). One researcher attended a community consultation for project in Freedom Park in which eight (8) women acted as representatives of the community . The authors visited the construction sites in March, July, August, October and November. Local driver and contacts with NGOs proved useful to guarantee safety and insight information. Some residents were informally interviewed before, during and after the construction with pictures and videos.

\subsubsection{Case Study: Netreg}

Development Action Group (DAG) a south African NGO acting as a support organisation for local communities initiated the project to build houses in Netreg.With the help of DAG the community identified land belonging to municipality and was subdivided into 192 plots of $81 \mathrm{~m} 2$ and was sold to the community beneficiaries at a sum below the market price.The construction started in 2004 and was completed in October 2006. However in 2005 Niall Mell $n$ foundation (NMF) got involved in the project and provided additional resources. NMF played a leading role in the architectural design and in the construction process.The design and location of the houses did not live up to the objectives of the Netreg Housing project.The settlement had one single access and was surrounded by high-speed highways which positionedNetreg settlement as a gated community isolated from surrounding communities. The community involvement decreased when NMF started to assume a leading role in the project.The community-based development approach is contradictory to the real needs of development in Netreg.The major problem was not of little representation but was the isolation of Netreg community from the large society of Bonteheuwel.

\subsubsection{Case Study: Freedom Park}

This project was occupied by informal dwellers located between two well-established low-income settlements in the township of Mitchells.DAG assisted in the steering committee in developing the project through a strong community-based approach.Due to the conflicts mostly based on violent disputes between gangs that belong to the two opposing communities, the Freedom park urban design (developed by an urban design company based in cape town) gave priority to the security of the new settlement which was accepted by the community.The layout resulted in an enclosed settlement (gated settlement) with only four entries and with roads not accessible to the urban fabric.The settlement reinforced fragmentation of the township and disturbed the functioning of the urban fabric.

\subsubsection{Case Study: Mfuleni}

Mfulleni Township is located about $40 \mathrm{~km}$ outside Cape Town which was developed by the local authority as a Site-and-Service initiative to relocate squatters who had illegally occupied land. The residents were given individual plots that included serviced connections and a portable pre-fab toilet. The residents built informal houses on the plots and NMF came in to replace the informal shacks by $42 \mathrm{~m} 2$ concrete block detached houses. Due to the location in the middle of plots, backyard shacks were deliberately discouraged which used to help residents have home based economic activities like shops, stores, garages etc. Despite this the community (represented by the committee) accepted the help of the NMF and was enthusiastic about the promises of building 209 "decent" detached houses.

\subsection{Conclusion}

This case study of three (3) case studies from South Africa was highlighted institutional and individual constraints and weaknesses. All three case studies showed the involvement of the local individuals and community in decision making (ownership) process but not so effective in terms of 
sustainable development and empowerment.Issues like incentives and budget where provided by NMF and DAG. Cost and Benefits were mostly seen in short term benefits only like the freedom park gated community .Institutional and organisation setup was not will implemented without the involvement of necessary professional advice at early stages. The three case studies are victims of wrong community-based approach in which the communities participated and accepted the proposal and help fromNFP through the steering committees and supported by DAG. Community participation was wrongly implemented .The performance of low-cost housing project did not really depend on community participation. In reality the performance of low-cost housing projects depend on a more complex interaction of participants, interests, objectives, resources and processes that go beyond the short term benefits of the participants.Some of the mechanism and advantages of community participation needed to be reconsidered in low-cost housing projects.

\section{Analysis of the Cases and Conclusion}

The phenomenon of participation, the ideals and practice were applied in both empirical case studies in Tanzania water project and South Africa housing projects.Both cases showed the involvement of external agencies (power) in trying to empower the communities with basic needs water and housing.They may be different types of projects but to some extent the way the community participate and get involved in projects can lead to different outcomes. Both case studies didn't have issues or evidence of ethnicity .Representation itself is not enough to ensure that the needs of the poor and marginalised are met.Well-structured institutions and Associations with the right representatives and professionals from the community can achieve the intended targets according to the two cases studied. Case study 1 describes the effectiveness of a formalised Institutional Association using professionalism with minimal participation (ownership) of the community and Case Study 2 on the other hand describes ineffectivenesscommunity and citizen participation in decision making. In conclusion what the policy makers try to achieve by introducing civic and community participation in policy formation and implementation needed to be reconsidered and the actual discrepancies between policy intentions and policy outcomes regarding participation depends on thestatus of the institutions and involvement of the right citizen participation (professionals as well).

\section{REFERENCES}

Clever, F (1999),'Paradoxes of Participation: Questioning participatory approaches to development" In: Journal of International Development, 11 pp.597-612

Botes, L and D van Rensburg (2000),"Community Participation in development: Nine Plagues and Twelve commandments" In Community Development Journals Vol.35 No.1 41-58

Irvin, R and J Stansbury, 2004, "Citizen Participation in decision making: Is it worth the effort?" In; public Administration review Jan/Feb 2004; 64; 1

Mompati, T and G.Prinsen, 2000/2011,'Ethnicity and participatory development methods in Botswana: Some participants are to be seen and not heard "In: A.Cornwall, 2011, the participation reader, Zed books, London / New York.

Stiglitz, J.2002, "Participation and Development: perspective from the Comprehensive Development Paradigm" In: Review of Development Economics 6 (2) 163-182

Stifel, M and M.Wolfe, 1994/2011,"the many faces of Participation" in A Cornwall, 2011, The Participation reader, Zed books, London / New York

F Cleaver and A Tonner 2006, the evolution of community water governance in Uchira, Tanzania: The implications for equality of access, sustainability and effectiveness UNHABITAT

G Lizarralde and M Massyn, 2008 unexpected negative outcomes of community participation in lowcost housing projects in South Africa, UNHABITAT 